\title{
PERENCANAAN LANSKAP WISATA SEJARAH UNTUK MENUNJANG ADAPTIVE REUSE GEDUNG JUANG 45 BEKASI JAWA BARAT
}

\section{Historical tourism landscape planning for the adaptive reuse of Gedung Juang 45 Bekasi, West Java}

\author{
Bagus Sajiwo \\ Landscape Planning \& Design \\ Officer, PT. Alam Sutera Realty \\ Email:Bagusjiwo9@gmail.com \\ Vera D Damayanti \\ Staf Pengajar Departemen \\ Arsitektur Lanskap, Fakultas \\ Pertanian IPB
}

\begin{abstract}
Gedung Juang 45 Bekasi (GJ45B) is a historical site as a legacy from the colonial period, located in Bekasi District, West Java Province. The site has been neglected due to unsuitable site utilization and lack of concern from the local government with respect to preserve the area. The objectives of this study are: (1) to identify the historical value and landscape character of GJ45B, (2) to analyze the potential and constraints of the site to be developed as a historical tourism site, and (3) to develop a concept and site plan for historical tourism of GJ45B site through spatial, circulation, activity, and facility programs which support historical interpretation of the site. The study was conducted through a planning process consisted of preparation, inventory, analysis, concept, synthesis, and site planning. The analysis applied descriptive and spatial approach by using scoring and weighting to physical, historical, and tourism aspects and subsequently resulted three suitability zones for historical tourism development with high, medium, and low values. The conceptual plan for the site is that GJ45B is designed for an educational and recreational historical tourism site by developing historical interpretation of Bekasi District and particularly of GJ45B. The final output of the study is a site plan including spatial, circulation, activities and facilities plans.
\end{abstract}

Keywords: historical site, tourism object, landscape planning, adaptive reuse, Gedung Juang, Bekasi

\section{PENDAHULUAN}

Indonesia memiliki pengalaman sejarah yang panjang dengan beragam periode kesejarahan yang menyisakan artefak bersejarah dalam bentuk obyek dan lanskap kesejarahan. Berbagai obyek dan lanskap sejarah terutama yang bernilai signifikan, harus dikonservasi karena merupakan fakta fisik dan arkeologi dari warisan sejarah dan budaya yang berkontribusi untuk kepentingan ekonomi masyarakat (Goodchild 1990). Untuk mendukung kelestarian obyek dan lanskap kesejarahan, salah satu pendekatannya yaitu melalui penggunaannya kembali secara adaptif (adaptive reuse). Adaptive reuse merupakan pemanfaatan kembali tapak atau struktur dengan peruntukan yang baru; salah satu contohnya yaitu sebagai obyek wisata. Lebih lanjut terkait dengan pengembangan wisata secara umum, terdapat lima komponen yang perlu diperhatikan yaitu: daya tarik, pelayanan, transportasi, promosi dan informasi (Gunn, 1993).

Gedung Juang 45 Bekasi (GJ45B) merupakan salah satu obyek bersejarah di Kabupaten Bekasi yang dibangun pada masa kolonial Belanda. Selain bernilai sejarah, gedung ini memiliki keunikan gaya arsitektur yang menjadi daya tarik tersendiri. Sayangnya kondisinya saat ini cenderung tidak terpelihara terutama dengan adanya penggunaan tapak yang tidak sesuai dan kurangnya perhatian dari pemerintah Kabupaten Bekasi terhadap keberadaan tapak bersejarah ini. Oleh karena itulah, Pemerintah Kotamadya Bekasi yang berbatasan dengan Kabupaten Bekasi, berinisiatif untuk menyusun rencana yang mendukung pelestarian GJ45B. Perhatian dari pemerintah kotamadya ini dilandasi oleh adanya pemikiran bahwamengingat sejarah Kotamadya Bekasi di masa lalu tak lepas dengan wilayah Kabupaten Bekasi, maka GJ45B pun menjadi bagian penting bagi bagi Bekasi pada umumnya.

Penelitian ini bertujuan untuk mendukung rencana inisiasi tersebut melalui perencanaan lanskap GJ45B. Konsep yang mendasari rencana laskap secara garis besar yaitu menjadikan GJ45B sebagai obyek wisata untuk mendukung penggunaannya kembali secara adaptif yang diharapkan mampu memberikan manfaat bagi masyarakat luas. Bentuk wisata yang dikembangkan berupa wisata sejarah yang direncanakan dapat menginterpretasikan nilai-nilai kesejarahan yang terkandung di dalamnya. Hasil penelitian ini diharapkan menjadi bahan rujukan bagi pemerintah setempat beserta pihak terkait lainya dalam upaya pengembangan dan pelestarian GJ45B.

\section{METODE}

\section{Lokasi dan Waktu Penelitian}

Studi ini dilakukan di daerah Tambun, tepatnya Jl. Sultan Hasanudin, Kelurahan Mekar Sari, Kecamatan Tambun Selatan, Kabupaten Bekasi, Jawa Barat (Gambar 1) dengan luas tapak sekitar $1,78 \mathrm{Ha}$. Studi perencanaan lanskap ini dimulai dari bulan Februari hingga Juli 2013.

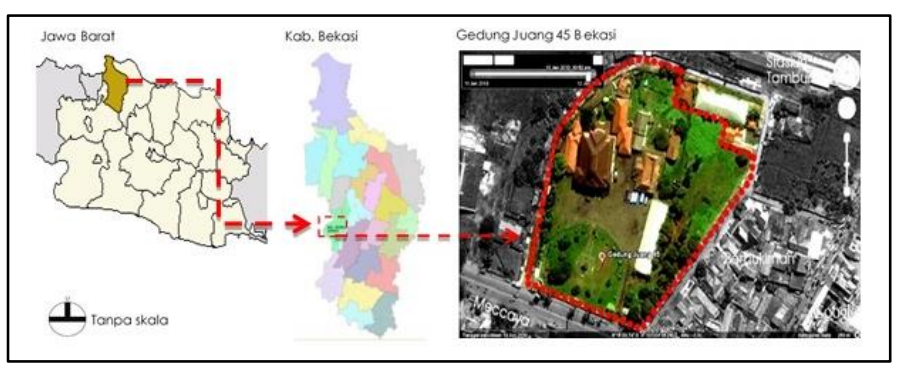

Gambar 1. Lokasi Penelitian Sumber : Google.com, maps.google.co.id 
Tabel 1. Kriteria analisis

\begin{tabular}{|c|c|c|c|c|c|}
\hline No. & Aspek & Bobot & Variabel & Kriteria & Skor \\
\hline I. & Bio-fisik & 30 & & & \\
\hline 1 & $\begin{array}{l}\text { Tata Guna } \\
\text { Lahan }\end{array}$ & & $\begin{array}{l}\text { Kondisi tapak dengan } \\
\text { penggunaan menurut RTRW }\end{array}$ & Deskriptif & \\
\hline 2 & Iklim & & Kenyamanan untuk aktifitas & Deskriptif & \\
\hline 3 & Tanah & & Kesesuaian & Deskriptif & \\
\hline 4 & Visual & & Kualiatas visual tapak & Deskriptif & \\
\hline 5 & Topografi & 30 & $\begin{array}{l}\text { Keamanan untuk pengembangan } \\
\text { wisata }\end{array}$ & $\begin{array}{l}\text { Sesuai } 0-15 \% \\
\text { Cukup sesuai } 15- \\
25 \% \\
\text { Tidak sesuai >25\% }\end{array}$ & $\begin{array}{l}3 \\
2 \\
1\end{array}$ \\
\hline 6 & Hidrologi & & Ketersediaan & Deskriptif & \\
\hline 7 & Vegetasi & & Jenis, jumlah dan distribusi & Deskriptif & \\
\hline II. & Kesejarahan & 35 & & & \\
\hline \multirow[t]{2}{*}{1} & \multirow[t]{2}{*}{ Keaslian } & \multirow[t]{2}{*}{17.5} & \multirow[t]{2}{*}{ Kondisi situs } & $\begin{array}{l}\text { Keaslian lebih dari } \\
80 \%\end{array}$ & 3 \\
\hline & & & & $\begin{array}{l}\text { Keaslian 30-80\% } \\
\text { Keaslian <30\% }\end{array}$ & $\begin{array}{l}2 \\
1\end{array}$ \\
\hline 2 & Keunikan & \multirow{5}{*}{17.5} & \multirow{5}{*}{$\begin{array}{l}\text { Nilai situs } \\
\text { Kondisi situs } \\
\text { Kondisi situs }\end{array}$} & Deskriptif & \\
\hline 3 & Nilai sejarah & & & Deskriptif & \\
\hline \multirow[t]{3}{*}{4} & \multirow[t]{3}{*}{ Keutuhan } & & & Keutuhan $>80 \%$ & 3 \\
\hline & & & & Keutuhan 30-80\% & 2 \\
\hline & & & & Keutuhan $<30 \%$ & 1 \\
\hline 5 & Estetika & & Kondisi situs & Deskriptif & \\
\hline 6 & Kejamakan & & Kondisi situs & Deskriptif & \\
\hline 7 & Keistimewaan & & Nilai situs & Deskriptif & \\
\hline III. & Wisata & & & & \\
\hline 1 & $\begin{array}{l}\text { Atraksi/Obyek } \\
\text { Wisata }\end{array}$ & 35 & Jenis & $\begin{array}{l}\text { Kerentanan elemen } \\
\text { tinggi } \\
\text { Kerentanan elemen } \\
\text { sedang } \\
\text { Kerentanan elemen } \\
\text { rendah }\end{array}$ & $\begin{array}{l}2 \\
3\end{array}$ \\
\hline 2 & $\begin{array}{l}\text { Sarana/ } \\
\text { Prasarana }\end{array}$ & & Jenis dan kondisi & Deskriptif & \\
\hline 3 & Pengunjung & & Persepsi dan Preferensi & Deskriptif & \\
\hline 4 & Aksesibilitas & & Ketersediaan dan kondisi fisik & Deskriptif & \\
\hline 5 & $\begin{array}{l}\text { Kebutuhan } \\
\text { Pengelola }\end{array}$ & & - & Deskriptif & \\
\hline 6 & $\begin{array}{l}\text { Peraturan dan } \\
\text { kebijakan }\end{array}$ & & $\begin{array}{l}\text { Peraturan terkait pelestarian dan } \\
\text { pengembangan }\end{array}$ & Deskriptif & \\
\hline
\end{tabular}

Sumber: Gunn (1993), Harris dan Dines (1988), Nurisjah dan Pramukanto (2001), Hardjowigeno et al. (1994) Modifikasi

\section{Metode penelitian}

Penelitian dilakukan dengan menggunakan tahapan perencanaan yang meliputi persiapan, inventarisasi, analisis, konsep, sintesis dan perencanaan lanskap (Gold 1980 dengan modifikasi).

(1) Persiapan: pada tahap ini dilakukan penetapan tujuan dan pengumpulan informasi awal mengenai tapak sebagai bahan untuk mengajukan usulan penelitian, serta perumusan masalah, batasan penelitian, dan pengurusan perijinan penelitian pada pihak-pihak terkait.

(2) Inventarisasi: dilakukan untuk pengumpulan data dan informasi terkait tapak dengan megumpulkaan data primer dan sekunder melalui metode survei lapang dan studi pustaka. Data yang dikumpulkan meliputi aspek fisik dan biofisik, aspek kesejarahan dan aspek wisata.

(3) Analisis: untuk memenuhi tujuan identifikasi karakter tapak dan potensi kendala pengembangan wisata di GJ45B. Metode analisis secara deskriptif dan spasial terhadap aspek fisik dan biofisik, kesejarahan, dan aspek wisata. Aspek fisik dan biofisik dianalisis secara deskriptif dengan modifikasi pada bagian analisis topografi yang dianalisis dengan teknik skoring menggunakan klasifikasi kemiringan menurut pedoman penyusunan pola rehabilitasi lahan dan konservasi tanahmenurut Dudal dan Soepraptohardjo (1975) dalam 
Hardjowigeno (1994) dan standar pengembangan tapak oleh Harris dan Dines (1988). Analisis aspek kesejarahan menggunakan kriteria penilaian nilai kesejarahan lanskap (Nurisjah dan Pramukamto 2001), dimana teknik skoring diaplikasikan pada analisis elemen keaslian dan keutuhan. Sementara itu analisis aspek wisata menggunakan referensi analisis obyek wisata yang dikemukakan oleh Gunn (1993), dengan modifikasi berupa analisis dengan skoring pada elemen atraksi wisata. Hasil analisis ketiga aspek tersebut dispasialkan dalam bentuk peta analisis dan masing-masing diberi bobot dimana aspek fisik/biofisik sebesar 30\%, kesejarahan $35 \%$, dan wisata $35 \%$. Peta hasil analisis ketiga aspek tersebut dioverlaydan menghasilkan peta komposit berupa zona kesesuaian wisata sejarah.

(4) Konsep: pada tahap ini disusun konsepdasar lanskap wisata GJ45B yang dikembangkan menjadi konsep interpretasi, ruang, sirkulasi, vegetasi, aktivitas dan fasilitas dengan menggunakan pendekatan kesejarahan dan kegiatan wisata dalam pengembangannya.

(5) Sintesis: penentuan ruang berdasarkan hasil analisis dan konsep untuk menghasilkan rencana blok. Tahap ini dikerjakan secara simultan dengan penyusunan konsep untuk menghasilkan rencana lanskap yang terarah dengan baik.

(6) Perencanaan Lanskap: pengembangan rencana blok menjadi rencana lanskap yang menggambarkan keadaan tapak setelah pengembangan; mencakup pembagian ruang, jalur sirkulasi, aktivitas dan fasilitas.

\section{HASIL DAN PEMBAHASAN}

\section{Kondisi Umum Tapak}

Secara geografis Kabupaten Bekasi terletak pada posisi $6^{\circ} 10^{\prime} 53^{\prime \prime}$ - 6 60 $^{\prime} 6^{\prime \prime}$ Lintang Selatan dan $106^{\circ} 48^{\prime} 28^{\prime \prime}$ - 107 $27^{\prime} 29^{\prime \prime}$ Bujur Timur atau terletak pada bagian utara dari Provinsi Jawa Barat dengan luas wilayah 127.388 Ha (BAPPEDA, 2012). Batas administrasi wilayah ini pada bagian utara berbatasan dengan Laut Jawa, Selatan berbatasan dengan Kabupaten Bogor, Barat berbatasan dengan DKI Jakarta dan Kota Bekasi, dan Timur berbatasan dengan Kabupaten Karawang.

GJ45B memiliki luas 1,78 Ha dan terletak di Jl. Sultan Hasanudin No. 5 Kelurahan Mekar Sari Kecamatan Tambun Selatan, Kabupaten Bekasi, Jawa Barat. Secara geografis GJ45B berada pada koordinat 6015'33"LS-10703'17"BT. Batas tapak di sebelah utara yaitu Stasiun Tambun, sebelah selatan dengan Jl. Sultan Hasanudin, sebelah timur dengan pemukiman, dan sebelah barat dengan lahan kosong. Saat ini GJ45B difungsikan sebagai gudang obat, kantor Dinas Pemadam Kebakaran Kabupaten Bekasi dan Kanminvet
(Kantor Administrasi Veteran) Bekasi. Gambar 2 menunjukan kondisi eksisting tapak.

\section{Data dan Analisis}

Sebagaimana telah dijelaskan padabagian metodologi bahwa analisis dilakukan pada aspek fisik/biofisik, kesejarahan, dan wisata. Sebagianbesar elemen dianalisis secara deskriptif dan analisisskoring dilakukan pada elemen topografi pada aspek fisik/biofisik, keaslian dan keutuhan pada aspek kesejarahan, dan atraksi wisata pada aspek wisata.

\section{Aspek Fisik dan Biofisik}

\section{(1) Tata Guna Lahan Sekitar Tapak}

Menurut Rencana Tata Ruang Wilayah (RTRW) Kabupaten Bekasi tahun 2009, Kecamatan Tambun Selatan diperuntukan sebagai kawasan industri. Pola perkembangan pada kawasan di sekitar tapak sebagian besar mengikuti alur sirkulasi/jalan. Hal ini menyebabkan perubahan penggunaan lahan yang berdampak terhadap aspek sosial maupun ekonomi masyarakat. Kondisi ini diperkirakan dapat mengancam keberadaan GJ45B sebagai area bersejarah yang berbatasan langsung dengan Jl. Sultan Hasanudin yang merupakan jalan utama penghubung Kota dan Kabupaten Bekasi.Letaknya yang strategis menjadikan tapak rentan akan pembangunan fisik yang lebih menekankan faktor ekonomis tanpa memperhatikan faktor kesejarahan. Perencanaan pemanfaatan GJ45B dengan memperhatikannilai historisnya diharapkan dapat mendukung kelestariannya.

\section{(2) Iklim}

Suhu di Kabupaten Bekasi berkisar antara 28-32oC dengan tingkat kelembaban $80 \%$ dan radiasi sebesar $66 \%$ (BAPPEDA, 2009 dan BMG, 2013). Kondisi tersebut menunjukan bahwa tapak memiliki iklim yang kurang nyaman dan cukup terik. Suhu dan kelembaban merupakan faktor utama penentu kenyamanan dan aktifitas manusia (Nurisjah dan Pramukanto, 2007). Untuk mengatasi ketidaknyamanan tersebut itu dapat dilakukan dengan memberikan fasilitas peneduh pada tapak berupa elemen softscape dan hardscape.

\section{(3) Tanah}

Jenis tanah daerah Tambun termasuk tipe asosiasi latosol coklat kemerahan dan latosol kekuningan (BP DAS Citarum, 2007). Menurut Dudal dan Soepraptohardjo (1975) tanah dengan tipe ini umumnya memiliki kandungan unsur hara dari rendah sampai sedang dengan infiltrasi dan perkolasi cukup cepat. Daya menahan air tipe tanah ini cukup baik dan tahan terhadap erosi. Dalam kaitannya untuk pengembangan kegiatan wisata, tanah latosol tergolong cukup baik 
sebab kondisi tanah latosol memiliki tekstur tanah halus hingga agak kasar (liat, berdebu, lempung, dan berpasir) yang dapat menopang konstruksi sederhana (Arsyad, 2000).

\section{(4) Visual}

Secara umum kondisi visual yang ada pada tapak didominasi oleh bangunan-bangunan tua dengan kondisi cukup buruk dan kotor serta vegetasi yang tumbuh tidak terawat disekitarnya. Hal ini menurunkan kualitas visual pada tapak. Kawasan GJ45B kini ditutupi oleh kios-kios pedagang kaki lima yang menyebabkan terhalangnya akses visual dari jalan raya ke arah gedung. Untuk pengembangan wisata di GJ45B maka perlu dilakukan penataan pada tapak dan sekelilingnya.

\section{(5) Topografi}

GJ45B berada pada ketinggian $30 \mathrm{mdpl}$, memiliki topografi yang relatif datar dengan kemiringan dominan berkisar antara $0-8 \%$ dan $8-15 \%$. Area dengan kemiringan $0-8 \%$ sesuai untuk pengembangan ruang luar dengan beragam kegiatan dan pengembangan elemen tapak dan diberi skor 3. Skor 2 diberikan pada area dengan kemiringan $8-15 \%$ sebab merupakan area cukup sesuai untuk beragam penggunaan namun jumlah dan jenis aktifitas yang dilakukan perlu dibatasi (Harris dan Dines, 1988). Pada halaman belakang tapak, kemiringan berkisar antara $25-45 \%$ dimana merupakan area yang kurang sesuai untuk penggunaan wisata dan rekreasi (Hardjowigeno, 1994) sehingga area ini diberi skor 1 .

\section{(6) Hidrologi}

GJ45B menggunakan sumber air berupa air tanah yang diperoleh dengan menggunakan pompa air. Pompa air dalam tapak ini sebenarnya kurang baik digunakan sebagai sumber bagi utilitas dalam tapak karena menurut data BAPPEDA (2012) sebagian besar sumber air di Kabupaten Bekasi merupakan air tanah dangkal yang berada pada kedalaman 5-25 mdari permukaan tanah sehingga dikhawatirkan dapat memberi pengaruh negatif pada tapak dan sekitarnya. Oleh karenanya disarankan sumber air untuk kegiatan dalam tapak menggunakan air pipa PDAM.

\section{(7) Vegetasi}

Vegetasi eksisting di GJ45B terdiri dari pohon, perdu, semak dan groundcover. Saat ini kondisi vegetasi pada tapak kurang tertata.Keberadaan vegetasi pada tapak kurang diketahui hubungannya dengan sejarah GJ45B. Jenis vegetasi yang ada diperkirakan bukan merupakan tanaman yang bernilai sejarah dilihat dari kurun waktu sejak dibangunnya gedung ini hingga setidaknya sampai tahun 1945. Adapun vegetasi di sekitar tapak sebelah barat berupa semak yang mengisi lahan kosong yang mengindikasikan penggunaan lahan sekitar tapak yang dulunya berupa lahan pertanian. Untuk mengetahui sejarah kondisi vegetasi pada tapak secara lebih rinci diperlukan studi lebih lanjut sejarah lanskapGJ45B melalui penelusuran dokumen kesejarahan.

\section{Aspek Kesejarahan}

\section{Sejarah singkat}

GJ45B dibangun pada masa kolonial Belanda antara 1906-1925 oleh tuan tanah berkebangsaan Tionghoa bernama Khouw Tjenk Kie yang dijuluki Tuan "Kapitaen". GJ45B memiliki lima bangunan yang terdiri dari satu bangunan utama yaitu GJ45B, dua paviliun, sebuah rumah dan sebuah bangunan mirip paviliun dengan ruangan yang lebih sempit. Gedung ini awalnya digunakan sebagai perkantoran Oenderneming (perkebunan) tuan tanah keluarga Khouw vanTamboen sekaligusberfungsi sebagaitempat pemungutan cukai perkebunan dan persawahan petani lokal pada masa itu. Hasil penarikan cukai padi kemudian disimpan di pabrik kongsi yang merupakan tempat pengolahan padi menjadi beras yang terletak di sebelah barat GJ45B. Pada masa pendudukan Jepang, tapak menjadi pusat pemerintahan Jepang. Kemudian pada masa kemerdekaan dan revolusi kompleks gedung ini menjadi markas tentara Indonesia dan tempat pelucutan senjata. Saat ini area ini menjadi kantor Dinas Pemadam Kebakaran dan Kanminvet.

\section{Penilaian Aspek Kesejarah GJ45B}

\section{(1) Keaslian}

Keaslian pada tapak dianalisis berdasarkan elemen pembentuk lanskap GJ45 pada masa lalu. Bangunan utama GJ45B, paviliun di bagian timur bangunan dan rumah yang terdapat di halaman belakang memiliki kondisi keaslian di atas $80 \%$ sebab kondisinya masih sama seperti saat masa kolonial Belanda. Area ini diberi skor 3. Pada bangunan di timur paviliun kedua terdapat perubahan bentuk bangunan menjadi kios kecil namun kondisi keaslian bangunan tersebut masih diatas $70 \%$. Batas tapak tetap sama namun penggunaan pagar kini sudah tidak asli. Berdasarkan kondisinya saat ini area tersebut diberi skor 2. Sedangkan area sekitar bangunan utama dan paviliun kondisinya sudah tidak asli. Hal ini terlihat dari dirobohkannya bangunan di bagian barat bangunan utama yang kini menjadi kantor veteran. Area tersebut diberi skor 1 .

\section{(2) Keunikan}

Keunikan yang dimiliki GJ45B terdapat gaya arsitektur bangunan yang mengandung unsur kolonial dan pecinan. Namun terdapat beberapa bangunan baru di 
sekitar GJ45B dengan gaya yang berbeda sehingga tidak terdapat kesatuan antar bangunan bangunan yang ada.

\section{(3) Nilai sejarah}

Peristiwa yang berlangsung di masa lalu merupakan peristiwa penting yang memiliki ikatan simbolis antara kejadian pada masa lalu dan juga sekarang (Nurisjah dan Pramukanto 2001). Peristiwa bersejarah yang berlangsung di GJ45B memiliki peran terhadap sejarah Indonesia terutama pada masa kolonial hingga masa kemerdekaan dan revolusi. Nilai sejarah yang dikandung oleh GJ45B dapat dikategorikan sebagai kejadian lokal terkait dengan peristiwa di tingkat nasional.

\section{(4) Keutuhan}

Kelengkapan elemen yang dibentuk oleh GJ45B sudah tidak lengkap disebabkan kondisi GJ45B yang tidak terawat dan kurangnya perhatian pemerintah setempat untuk melestarikan keberadaannya. Kondisi bangunan utama dan paviliun dalam tapak tergolong cukup baik dengan kondisi hampir 100\%. Area ini diberi skor 3. Bangunan di timur bagian paviliun keutuhannya sekitar $80 \%$ sehingga area ini diberi skor 2. Sedangkan untuk area sekitar tapak sudah mengalami banyak perubahan seperti dirobohkannya bangunan di bagian barat GJ45B dan diganti dengan kantor Kanminvet sehingga area tersebut diberi skor 1 .

\section{(5) Estetika}

Dilihat dari gaya dan susunan bangunannya, GJ45B memiliki nilai estetika yang menarik untuk dinikmati. Walaupun demikian GJ45B masih belum dapat dikatakan sebagai lanskap bersejarah dengan nilai estetika tinggi sebab GJ45B bukan merupakan sebuah karya lanskap dengan prestasi khusus dalam suatu gaya tertentu.

\section{(6) Kejamakan}

Kejamakan dalam penilaian lanskap sejarah mengacu pada mewakili atau tidaknya suatu lanskap terhadap periode sejarah (Nurisjah dan Pramukanto, 2001). GJ45B merupakan tipikal lanskap tempat tinggal tuan tanah pada periode Kolonial Belanda.

\section{(7) Keistimewaan}

Penilaian aspek sejarah untuk lanskap dengan keistimewaan ditujukan pada karya lanskap yang dapat dikategorikan sebagai sebuah masterpiece (Nurisjah dan Pramukanto 2001). GJ45B belum dapat dikatakan sebagai lanskap sejarah dengan yang memiliki nilai keistimewaan. Pengertian masterpiece ini dapat dikatakan cenderung menekankan aspek fisik atau performa rancangan tapak atau bangunan. Namun demikian secara non-fisik GJ45B memiliki nilai kesejarahaan penting dalam konteks berbagai persitiwa penting yang pernah terjadi didalamnya.

\section{(8) Persepsi masyarakat}

Hasil kuisioner menunjukan 90\% responden menganggap kondisi GJ45B kini sangat buruk dan sisanya melihat kondisinya cukup baik. Terkait sejarah Kabupaten Bekasi, 50\% responden tidak mengetahui, $13,33 \%$ sedikit mengetahuidan 36,67\% mengetahui. Sementara itu, mengenai sejarah GJ45B hanya $7 \%$ dari responden yang mengetahui, sekitar 36,67\% dan 56,67\% hanya sedikit mengetahui dan tidak mengetahuinya. Responden umumnya mengetahui sejarah GJ45B dari sekolah (33,33\%). Terkait rencana pengembangan GJ45B sebagai obyek wisata sejarah, sebagian besar responden setuju (63,33\%), sisanya menganggap cukup dilestarikan $(26,67 \%)$.

Persepsi masyarakat juga diperoleh melalui wawancara dengan pihak-pihak terkait seperti Kepala Dinas Pariwisata kebudayaan dan Olahraga dan serta pendapat ahli sejarah dan budayawan di kabupaten Bekasi. Narasumber berharap GJ45B dapat dikembangkan menjadi museum atau sebagai pusat informasi sejarah dan budaya Kabupaten Bekasi.

\section{Aspek Wisata}

\section{Daya tarik}

\section{(1) Daya tarik}

Daya tarikutama pada tapak adalah struktur bangunan (GJ45B dan empat bangunan penunjang), patung dan relief peringatan, lanskap sejarah, dan peristiwa sejarah yang terjadi di GJ45B dari masa kolonial Belanda hingga masa revolusi.

\section{(2) Sarana dan prasarana}

Sarana dan prasarana yang tersedia pada tapak berupa toilet, saluran sanitasi dan tempat parkir. Jumlah dan kondisi sarana-prasarana tersebut kurang jika tapak dikembangkan untuk mendukung obyek wisata.

\section{(3) Aksesibilitas dan Sirkulasi.}

GJ45B berjarak 15km dari Kota Bekasi dengan waktu tempuh 35 menit, sedangkan dari Kabupaten Bekasi, GJ45B berjarak $30 \mathrm{~km}$ dan ditempuh dengan waktu 60 menit, keduanya dengan menggunakan kendaraan umum. Akses masuk GJ45B berupa gerbang dengan lebar $5 \mathrm{~m}$ yang merupakan satu-satunya akses GJ45B. Dalam area GJ45B tidak terlihat adanya sirkulasi yang cukup 
jelas, setiap bangunan yang ada dihubungkan oleh area terbuka yang permukaannya ditutupi oleh kerikil.

\section{(4) Pengunjung}

Pengguna tapak saat ini selain pegawai DamKar dan Kaminvet, terdapat pula siswa beberapa SD dan Pendidikan Anak Usia Dini serta komunitas di Bekasi yang datang pada hari dan jam tertentu untuk memanfaatkan ruang terbuka di GJ45B. Keberadaan pengunjung umum dan juga pengunjung anak-anak pada tapak merupakan potensi wisatawan pada tapak. Diharapkan jika tapak dikembangkan sebagai obyek wisata pengunjung yang datang akan bertambah, baik dari segi asal maupun jumlahnya. Keberadaan pengunjung yang mendapatkan manfaat dari GJ45B secara tidak langsung akan mendukung keberlanjutan GJ45B sebagai obyek bernilai kesejarahan.

\section{(5) Peraturan dan kebijakan}

Aturan dan kebijakan yang membahas mengenai peran serta pemerintah Kabupaten Bekasi dalam pengembangan GJ45B sebagai aset sejarah masih sangat kurang. GJ45B yang diperkirakan telah berumur lebih dari 100 tahun tersebut hingga saat studi ini selesai dilakukan masih belum terdaftar sebagai benda cagar budaya(GJ45B kemudian diajukan sebagai BCB pada tahun 2015).

\section{Hasil Analisis}

Berdasarkan hasil overlay hasil analisis aspek topografi, nilai kesejarahan, dan daya tarik wisata dengan proporsi bobot 30:35:35, didapatkan area kesesuaian untuk pengembangan wisata tingkat tinggi, sedang, dan rendah (Tabel 2) dimana lokasi sebarannya pada tapak diperoleh melalui peta komposit (Gambar 2).

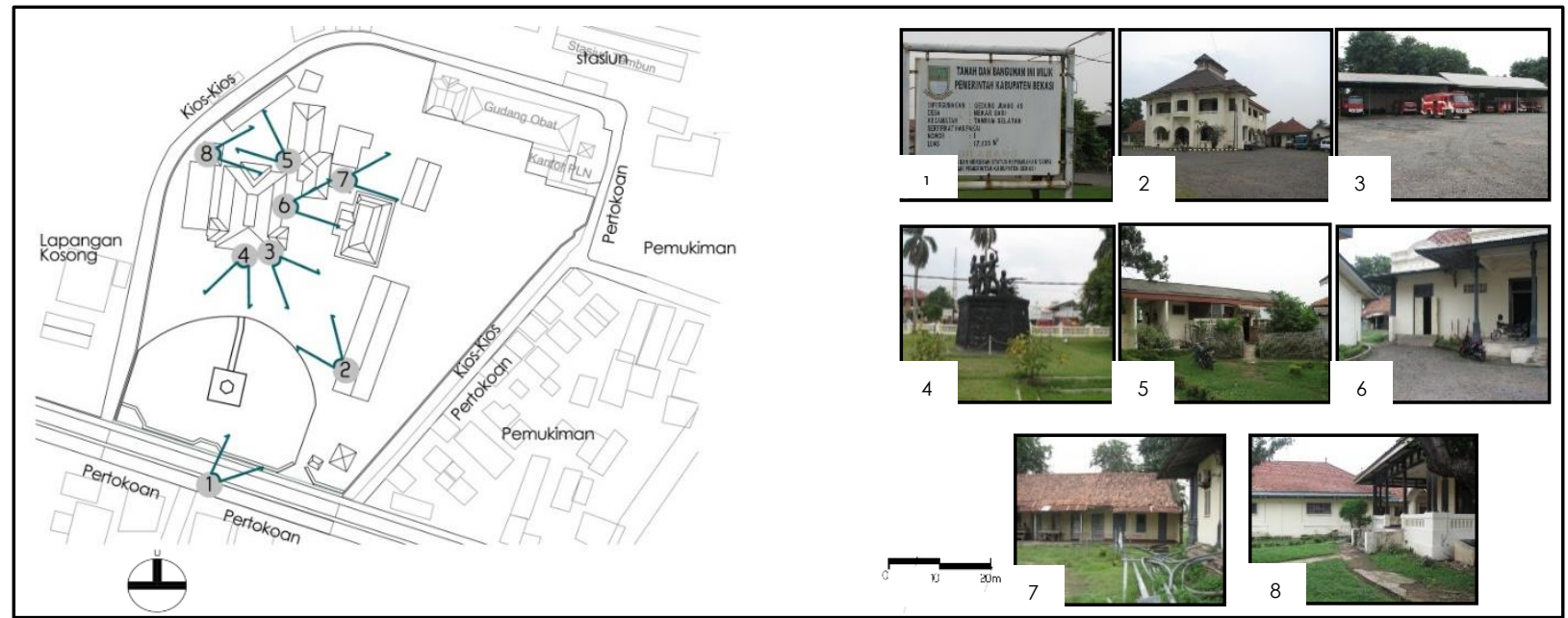

Gambar 2. Kondisi eksiting tapak

Sumber : Dokumentasi pribadi

Tabel 2. Tabel hasil analisis

\begin{tabular}{llccl}
\hline No & Zona Kesesuaian & Luas $\left.\mathbf{( m}^{\mathbf{2}}\right)$ & Prosentase (\%) & Keterangan \\
\hline 1 & Tinggi & $10.540,35$ & 59,22 & $\begin{array}{l}\text { kondisi fisik-lingkungan dan nilai sejarah angat mendukung untuk } \\
\text { kegiatan wisata sejarah daya tarik sejarah pada area ini tergolong tidak } \\
\text { terlalu rentan untuk kegiatan wisata. }\end{array}$ \\
\cline { 1 - 3 } 2 Sedang & $4.564,47$ & 25,64 & $\begin{array}{l}\text { area dengan kondisi fisik lingkungan yang cukup sesuai untuk kegiatan } \\
\text { wisata. nilai kesejarahan yang di kandung tidak terlalu tinggi dan memiliki } \\
\text { tingkat daya tarik yang tidak terlalu rentan untuk wisata. }\end{array}$ \\
\hline
\end{tabular}




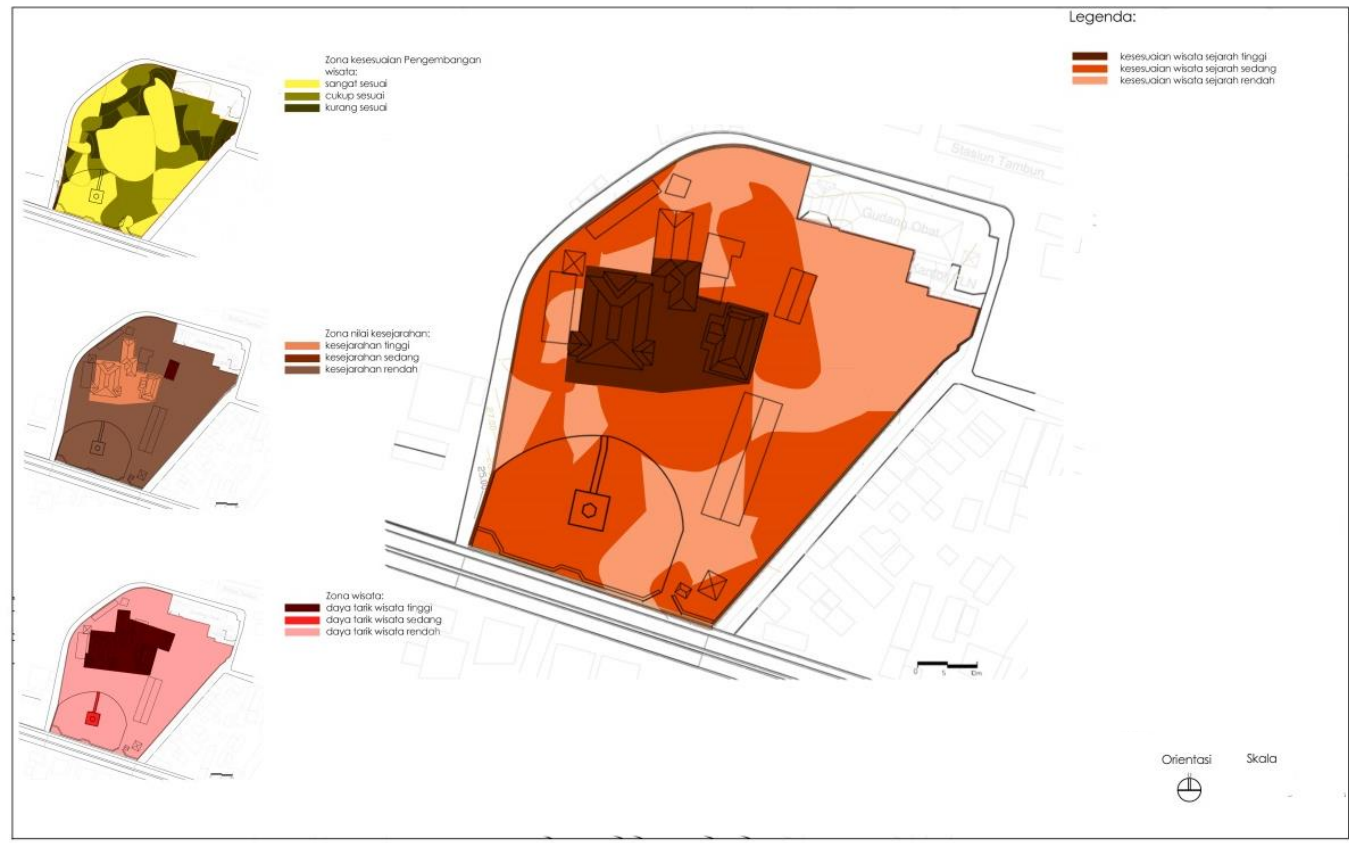

Gambar 3. Peta komposit hasil analisis

\section{Konsep}

\section{Konsep Dasar Perencanaan}

Konsep dasar perencanaan lanskap untuk tapak yaitu menjadikan GJ45B sebagai obyek wisata sejarah yang edukatif dan rekreatif serta mampu mendukung pelestarian sumberdaya sejarah pada tapak. Fungsi yang akan dikembangkan dalam tapak adalah fungsi wisata dan penyangga. Fungsi wisata berkaitan dengan kebutuhan wisatawan dalam bentuk obyek dan atraksi serta fasilitas penunjangnya dalam tapak. Fungsi penyangga dikembangkan untuk menjaga kondisi elemen dan lanskap sejarah GJ45B.

\section{Pengembangan Konsep}

(1) Konsep Interpretasi: interpretasi yang dikembangkan bertema Sejarah Bekasi pada masa kolonial Belanda sampai setelah masa revolusi. Pengunjung akan mendapatkan pengalaman berbeda pada tiap ruang yang dikembangkan dalam tapak melalui tampilan audio, visual, kinesthetic maupun simbol-simbol.

(2) Konsep Ruang: tapak dibagi berdasarkan penjabaran fungsi dan nilai kesejarahan, yang terdiri dari ruang penerimaan, ruang wisata, dan ruang penyangga. Ruang penerimaan berfungsi sebagai akses utama dan identitas tapak sehingga menarik minat pengunjung. Ruang wisata adalah ruang tempat aktivitas wisata berlangsung, terbagi menjadi ruang wisata utama dan ruang pendukung wisata (pelayanan). Ruang penyangga merupakan ruang yang dibuat untuk menjaga sumber daya tapak dari gangguan luar.
(3) Konsep Sirkulasi: sirkulasi yang akan dikembangkan terdiri dari sirkulasi primer yang menghubungkan antar ruang dalam tapak, serta sirkulasi sekunder yang menghubungkan sub-sub ruang dalam tapak. Sirkulasi wisata pada tapak akan mengarahkan pengunjung secara bertahap mempelajari sejarah Bekasi secara umum hingga sejarah GJ45B.

(4) Konsep Vegetasi: konsep vegetasi pada ruangruang yang ada pada tapak secara umum mengutamakan fungsi estetik, pengarah, pembatas antar ruang dan penaung.

(5) Konsep Aktivitas: Konsep aktivitas terbagi menjadi dua yaitu aktivitas edukatif dan aktivitas rekreatif.

(6) Konsep Fasilitas: Konsep fasilitas dalam tapak terbagi menjadi fasilitas wisata dan fasilitas non-wisata. Fasilitas wisata terbagi lagi menjadi fasilitas interpretasi dan noninterpretasi.

\section{Sintesis}

Berdasarkan kebutuhan ruang wisata dan upaya menjaga sumberdaya GJ45B, maka direncanakan penambahan luas sebesar $1.580 \mathrm{~m} 2$. Penambahan luas ini disebabkan luas tapak eksisting kurang memungkinkan untuk menampung seluruh aktifitas wisata dan pendukungnya yang akan dikembangkan di tapak. Area yang diperluas berada di bagian barat tapak.

\section{Rencana Blok}

Rencana blok membagi tapak menjadi empat ruang utama yaitu ruang penerimaan, pendukung wisata, wisata utama, dan penyangga. Dalam ruang wisata utama terdapat subsub ruang yaitu: sub-ruang interpretasi sejarah Bekasi, GJ45B, pertunjukan, themegarden, koleksi, kepustakaan, dan 
audiovisual. Gambar 4 menunjukan rencana blok pada tapak.

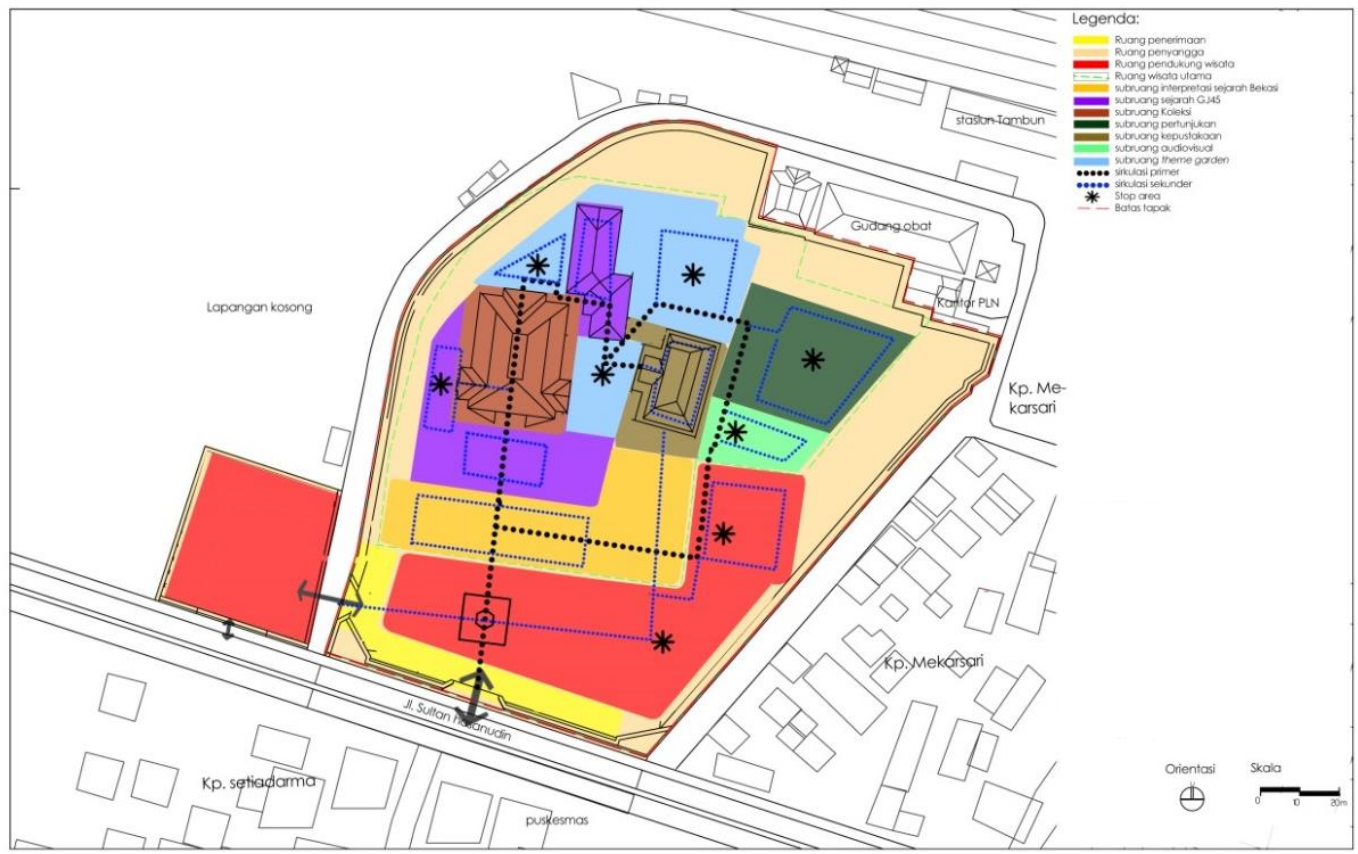

Gambar 4 Rencana blok

\section{Perencanaan lanskap}

\section{Rencana Ruang}

Tapak direncanakan terbagi atas ruang penerimaan, pendukung wisata, wisata utama, dan penyangga (Tabel 3). Jika diasumsikan jam operasional obyek wisata GJ45B dari jam 10.00-18.00, maka dalam sehari tapak memiliki daya tampung pengunjung sekitar 1.200 orang.

Sirkulasi primer yang menghubungkan ruang-ruang utama pada tapak memiliki lebar $2.5 \mathrm{~m}$, dan sirkulasi sekunder yang ada dalam ruang selebar $1,8 \mathrm{~m}$. Sirkulasi primer menjadi jalur interpretasi yang memiliki sekuens yang diawali dengan kesejarahan Kabupaten Bekasi secara umum kemudian semakin spesifik menuju sejarah GJ45B. Pada sepanjang jalur sirkulasi akan dilengkapi dengan site furniture (signage, bangku, tempat sampah, dan lampu) yang juga dapat difungsikan sebagai fasilitas interpretasi dan non-interpretasi untuk memenuhi kebutuhan pengunjung selama melakukan aktivitas.

\section{Rencana sirkulasi}

Sirkulasi primer yang menghubungkan ruang-ruang utama pada tapak memiliki lebar $2,5 \mathrm{~m}$, dan sirkulasi sekunder yang ada dalam ruang selebar $1,8 \mathrm{~m}$. Sirkulasi primer menjadi jalur interpretasi yang memiliki sekuens yang diawali dengan kesejarahan Kabupaten Bekasi secara umum kemudian semakin spesifik menuju sejarah GJ45B. Pada sepanjang jalur sirkulasi akan dilengkapi dengan site furniture (signage, bangku, tempat sampah, dan lampu) yang juga dapat difungsikan sebagai fasilitas interpretasi dan non-interpretasi untuk memenuhi kebutuhan pengunjung selama melakukan aktivitas.

Tabel 3. Tabel alokasi ruang

\begin{tabular}{|c|c|c|c|}
\hline No & Fungsi & $\begin{array}{c}\text { Luas } \\
\left(\mathrm{m}^{2}\right)\end{array}$ & $\begin{array}{c}\text { Proporsi } \\
(\%)\end{array}$ \\
\hline 1 & Ruang penerimaan & 935,75 & $5.17 \%$ \\
\hline 2 & Ruang pendukung wisata & $5.462,10$ & $30.17 \%$ \\
\hline 3 & $\begin{array}{l}\text { Ruang wisata utama (sub-ruang } \\
\text { interpretasi sejarah Bekasi, } \\
\text { GJ45B, koleksi, audiovisual, } \\
\text { pertunjukan, dan theme garden ) }\end{array}$ & $8.851,15$ & $48.90 \%$ \\
\hline 4 & Ruang penyangga & $2.853,35$ & $15.76 \%$ \\
\hline
\end{tabular}

\section{Rencana vegetasi}

Vegetasi yang direncanakan dipilih berdasarkan fungsi yang akan dikembangkan yaitu fungsi estetik, pengarah, peneduh dan pembatas. Pemilihan jenis vegetasi selain mempertimbangkan fungsi, juga memperhatikan kesesuaiannya dengan konteks nilai kesejarahan tapak (Tabel 4).

\section{Rencana aktivitas}

Berbagai kegiatan dalam tapak (Tabel 5) ditujukan untuk pengunjung GJ45B dengan semua tingkat usia. Aktifitas wisata dalam tapak pada ruang penerimaan, pendukung wisata, dan sub-wisata utama sejarah umum Bekasi berlangsung setiap hari. Sementara untuk waktuoperasi ruang wisata utama lainnya pada hari Selasa sampai dengan Minggudari pukul 10.00-18.00 WIB. Pengunjung dapat memasuki halaman depan GJ45B (ruang penerima, pendukung wisata, sub-wisata utama sejarah umum Bekasi) 


\section{SAJIWO, DAMAYANTI}

secara bebas, namun untuk memasuki area wisata utama pengunjung harus membeli tiket. Khusus untuk memasuki ruang audio-visual, pengunjung harus membayar tiket tambahan.

\section{Rencana fasilitas}

Karakter desain fasilitas yang dikembangkan menggunakan gaya kolonial dengan pengaruh pecinan. Jenis fasilitas sesuai dengan fungsi ruang (Tabel 6).

Tabel 4. Rencana vegetasi pada tapak

\begin{tabular}{|c|c|c|c|}
\hline No & Fungsi & Nama Botani & Nama Lokal \\
\hline \multirow[t]{9}{*}{1} & \multicolumn{3}{|l|}{ Estetika } \\
\hline & - $\quad$ rumput & $\begin{array}{l}\text { - Axonophus compressus 'Dwarf' } \\
\text { - Zoysia japonica }\end{array}$ & $\begin{array}{l}\text { - rumput gajah mini } \\
\text { - rumput jepang }\end{array}$ \\
\hline & \multirow[t]{3}{*}{ - $\quad$ semak } & - Acalypha siamensis & - acalypha \\
\hline & & - Bougainvillea & - bougenvill \\
\hline & & - Orthosiphon stamineus & - Kumis kucing \\
\hline & \multirow[t]{4}{*}{ - Pohon } & - Caesalpinia pulcherrima & - kembang merak \\
\hline & & - Roystonea regia & - palem raja \\
\hline & & - Salix babylonica & - janda merana \\
\hline & & - Thevetia peruviana & - kembang jepun \\
\hline 2 & Pengarah & Hibiscus rosasinensis & kembang sepatu \\
\hline \multirow[t]{10}{*}{3} & \multicolumn{3}{|l|}{ Pembatas antar ruang } \\
\hline & \multirow[t]{7}{*}{ - Penyangga } & - Begonia sp. & - begonia \\
\hline & & - Cannarium commune & - kenari \\
\hline & & - Casuarina equisetifolia & - cemara laut \\
\hline & & - Jacaranda mimosifolia & - jakaranda \\
\hline & & - Swietenia mahagoni & - mahoni \\
\hline & & - Tamarindus indica & - asam jawa \\
\hline & & - Terminalia catappa & - ketapang \\
\hline & \multirow[t]{2}{*}{ - $\quad$ pembagi ruang } & - Bambusa sp. & - bambu \\
\hline & & - Duranta erecta & - duranta \\
\hline \multirow[t]{3}{*}{4} & \multirow[t]{3}{*}{ Penaung } & Delonix regia & flamboyan \\
\hline & & Lagerstroemia speciosa & bungur \\
\hline & & Samanea saman & ki hujan \\
\hline
\end{tabular}

Tabel 5.Rencana aktifitas GJ45B

\begin{tabular}{|c|c|c|c|c|}
\hline No & Ruang & Sub Ruang & Fungsi & Jenis Aktifitas \\
\hline 1 & Ruang penerimaan & - & Entrance dan identitas tapak & akses keluar masuk tapak \\
\hline 2 & $\begin{array}{l}\text { Ruang Pendukung } \\
\text { Wisata }\end{array}$ & - & Pelayanan & $\begin{array}{l}\text { ticketing, belanja, makan, parkir, duduk- } \\
\text { duduk }\end{array}$ \\
\hline \multirow[t]{7}{*}{3} & \multirow[t]{7}{*}{ Ruang Wisata Utama } & $\begin{array}{l}\text { interpretasi sejarah } \\
\text { Bekasi }\end{array}$ & pengenalan sejarah Bekasi & interpretasi, photohunting \\
\hline & & interpretasi GJ45B & pengenalan sejarah GJ45B & interpretasi, pameran, photohunting \\
\hline & & koleksi & sarana interpretasi benda bersejarah di Bekasi & Pameran, photohunting \\
\hline & & kepustakaan & Pusat informasi Sejarah Bekasi & membaca, workshop, seminar \\
\hline & & pertunjukan & Ruang multi fungsi & $\begin{array}{l}\text { menonton, pameran outdoor, gathering, } \\
\text { event }\end{array}$ \\
\hline & & Theme garden & Pengenalan sejarah GJ45B (4 tema) & interpretasi, pameran, photohunting \\
\hline & & audiovisual & Pengenalan berbagai sejarah dan budaya Bekasi & Menonton, workshop, seminar \\
\hline 4 & Ruang penyangga & - & menjaga sumberdaya tapak & - \\
\hline
\end{tabular}

Tabel 6. Rencana fasilitas GJ45B

\begin{tabular}{lll}
\hline No. & Ruang & Fasilitas \\
\hline 1 & Ruang penerimaan & Signage, gerbang \\
\hline 2 & Ruang Pendukung Wisata & Loket, VIC, toilet, papan nama, kantin, toko souvenir, area parkir, tempat sampah, lampu \\
\hline 3 & Ruang Wisata Utama & $\begin{array}{l}\text { Papan interpretasi. bangku taman, jalur interpretasi, ruang audiovisual, papan interpretasi, sculpture, } \\
\text { Amphitheater, bangku, lampu, tempat sampah, }\end{array}$ \\
\hline 4 & Ruang penyangga & Jalur inspeksi \\
\hline
\end{tabular}




\section{Rencana tapak}

Produk akhir dari penelitian GJ45B ini berupa rencana tapak yang merupakan hasil pengintegrasian rencana ruang, sirkulasi, aktifitas dan fasilitas yang masing-masing telah dipaparkan sebelumnya. Hasil dari rencana tapak inidituangkan kedalam gambarsite plan (Gambar5) dilengkapi dengan potongan dan ilustrasi tapak (Gambar 6 dan 7).

Rencana tapak ini memiliki kelebihan dan kekurangan yang perlu untuk dievaluasi terkait manfaat dan dampaknya jika rencana ini nantinya diimplementasikan. Pada rencana tapak, di halaman utama terdapat ruang terbuka yang dapat diakses secara bebas oleh publik berupa plaza dimana ruang ini dapat dimanfaatkan untuk mendukung aktifitas khususnya bagi masyarakat di Kabupaten Bekasi, misalnya untuk pameran seni, pasar seni, dan pertunjukan seni. Adanya ruang publik ini nantinya menjadi nilai tambah bagi GJ45B. Sementara itu dalam rancangan ini terlihat bahwa secara keseluruhan tapak didominasi oleh perkerasan yang di satu sisi dapat mendukung aktifitas yang intensif pada tapak. Namun di sisi lain konstruksi tersebut memberikan dampak mengurangi tingkat keaslian tapak dari sudut pandang kesejarahan. Pada kondisi tertentu, kasus seperti ini terkadang tidak dapat dihindari dan perubahan ini pada akhirnya menjadi bagian dari sejarah fisik tapak.
Dengan mempertimbangkan tapak dalam konteks lokasinya terhadap sekitarnya, aspek yang potensial untuk digali lebih lanjut yaitu menciptakan koneksi ruang antara obyek wisata GJ45B dengan beberapa titik penting disekitarnya, terutama dengan Stasiun Kereta Api Tambun di sebelah utara dan kawasan Pasar Tambun di sebelah timur di jalan utama menuju GJ45B. Stasiun kereta merupakan salah satu akses bagi pengunjung dari luar kawasan menuju GJ45B. Pengembangan ruang transisi antara stasiun dengan GJ45B dengan merancang koridor yang atraktif melalui tema terkait kesejarahan tidak hanya menciptakan hubungan ruang namun juga menambah pengalaman rekreatif bagi pengunjung. Sementara itu, dengan merencanakan area kuliner di Pasar Tambun diharapkan dapat mengakomodir kebutuhan pengunjung terhadap kebutuhan makan-minum sekaligus menawarkan ruang rekreasi alternatif bertemakan kulinari. Pengintegrasian ini ditujukan untuk: (1) membangun unity sehingga kawasan membentuk suatu lanskap destinasi wisata dengan kesejarahan sebagai tema utama; (2) memperkaya pengalaman berwisata; serta (3) dapat mengakomodir kebutuhan pengunjung; yang pada akhirnya ketiganya diharapkan mampu memenuhi kepuasan mereka dalam berwisata.

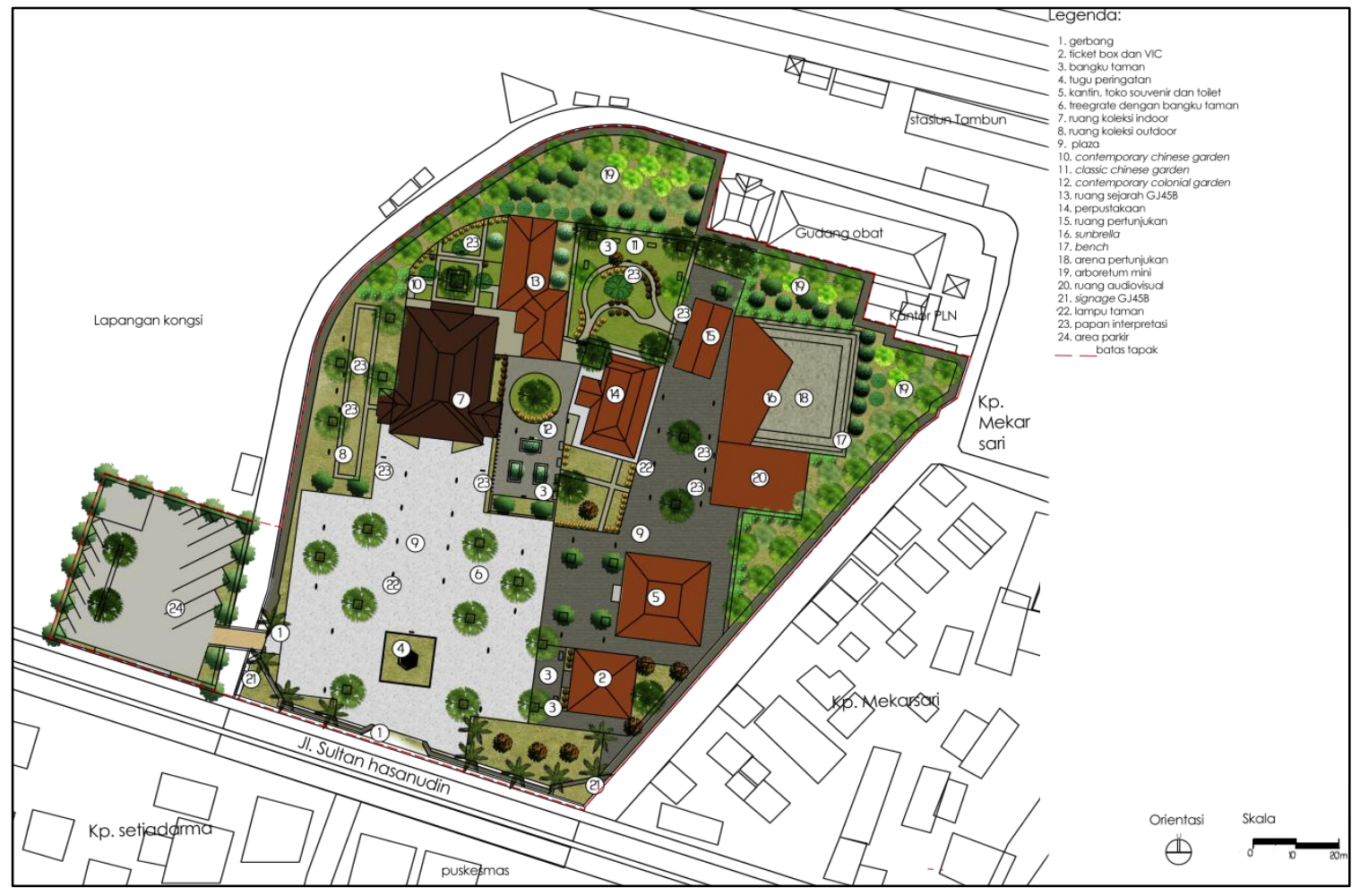

Gambar 5. Rencana Tapak GJ45B 


\section{SAJIWO, DAMAYANTI}

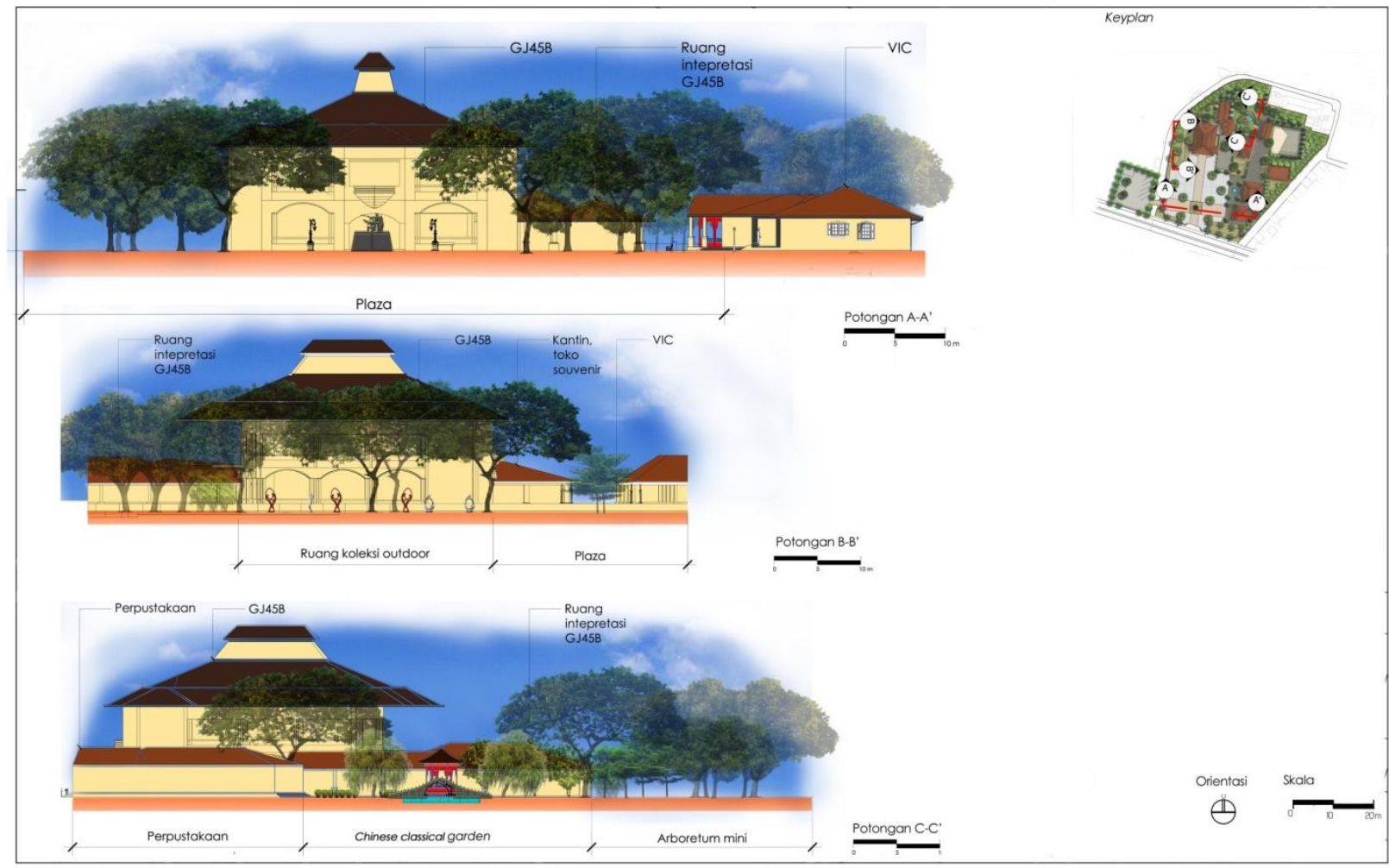

Gambar 6. Gambar tampak potongan area penerimaan sebagai penunjang rencana tapak

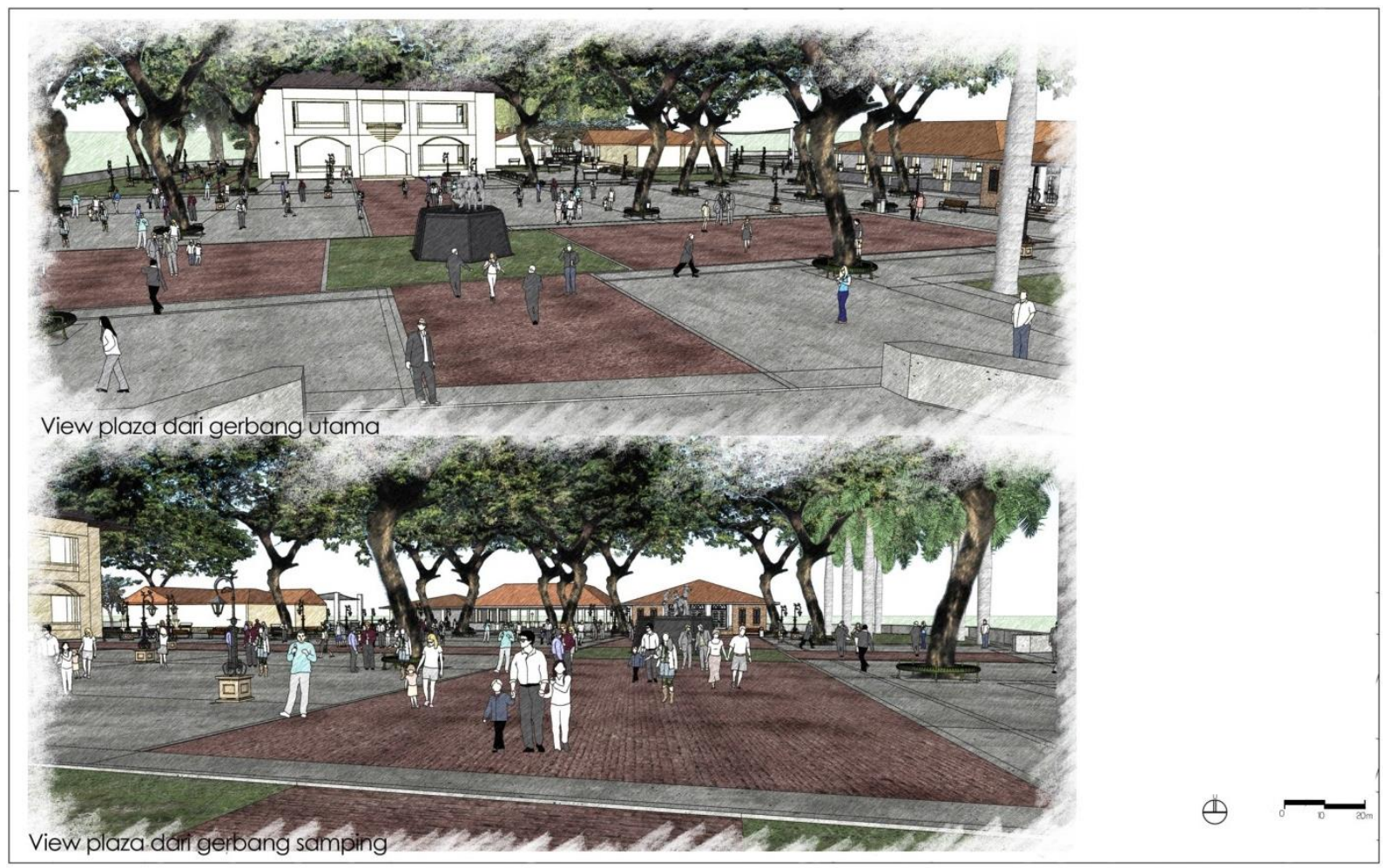

Gambar 7. Gambar ilustrasi perspektif 3D area penerimaan sebagai penunjang rencana tapak

\section{SIMPULAN}

Berdasarkan hasil identifikasi nilai sejarah, GJ45B memiliki peran penting dalam kesejarahan Indonesia, dimulai dari masa kolonial Belanda, pendudukan
Jepang, dan masa Revolusi. Namun, karakteristik lanskap sejarah GJ45B sudah tidak terlihat karena penggunaan yang tidak sesuai dan kurang terawat. Pengembangan tapak sebagai obyek wisata sejarah yang 
diajukan melalui studi ini merupakan salah satu pendekatan untuk pemanfaatan adaptif lanskap kesejarahan GJ45B. Hasil analisis pada studi ini menghasilkan tiga zona kesesuaian pengembangan wisata sejarah yang bernilai tinggi $(59,22 \%)$, sedang $(25,64 \%)$, dan rendah $(14,14 \%)$. Pengembangan tapak untuk kegiatan wisata sebaiknya didukung dengan penambahan area di sekitar tapak karena luasan tapak kurang memadai untuk fasilitas pendukung wisata serta dengan pertimbangan untuk menjaga sumberdaya tapak. Konsep lanskap obyek wisata GJ45B yaitu menjadikan GJ45B sebagai obyek wisata sejarah yang edukatif dan rekreatif sebagai pusat informasi sejarah dan budaya Kabupaten Bekasi melalui pengembangan interpretasi yang secara tidak langsung mendukung pelestarian tapak. Konsep tersebut diwujudkan dalam rencana tapak yang mencakup rencana ruang, sirkulasi, vegetasi, aktifitas dan fasilitas.

Pengembangan dapat dilakukan secara bertahap untuk menciptakan kawasan wisata sejarah yang terintegrasi dengan baik. Sebaiknya dilakukan studi historis arsitektural maupun lanskap GJ45B sebagai dasar pengembangan GJ45B yang lebih komprehensif. Untuk mempopulerkan GJ45B sebagai obyek wisata sejarah maka perlu dilakukan promosi dan penyediaan informasi agar dapat lebih dikenal dan menarik minat wisatawan untuk berkunjung. Selain itu integrasi tapak dengan sekitarnya juga dapat dilakukan untuk menunjang obyek wisata sejarah GJ45B, terutama melalui revitalisasi kawasan pecinan yang ada di bagian timur tapak dan menciptakan koidor koneksi dengan Stasiun Tambun.

\section{UCAPAN TERIMA KASIH}

Ucapan terima kasih disampaikan kepada Dinas Pertamanan Kotamadya Bekasi Jawa Barat yang menjadikan studi perencanan lanskap ini sebagai bagian dari program kegiatan sehingga penulis mendapatkan bantuan dana operasional dan data.

\section{DAFTAR PUSTAKA}

Arsyad, S. 2000. Konservasi Tanah dan Air. Bogor (ID): Lembaga Sumberdaya Informasi IPB Press.

Bappeda. 2012. Kabupaten Bekasi Dalam Angka. Bekasi (ID):Bappeda Kabupaten Bekasi.

Disparbudpora. 2010. Penyusunan Draft Raperda Seni dan Budaya Tahun Anggaran 2010. Jakarta (ID):Tranadi Tatautami.

Gold S. M. 1980. Recreation Planning and Design. New York (US): McGraw Hill Book.

Goodchild P.H. 1990. Some Principal For Conservation of Historic Landscape. [Draft

Document for Discussion Purpose]. Canada:
Icomos (UK) Historic Gardens and Landscape Comittee. p 43-48.

Gunn C. A. 1993. Tourism Planning, Basic, Concept, Cases. Washington (US): Taylor and Francis

Harris C. W, Dines N. T. 1988. Time Saver

Standards for Landscape Architecture. New York (US): The McGraw-Hill Companies, Inc.

Hardjowigeno, S. 1994. Kesesuaian Lahan Untuk Pengembangan Pertanian, Daerah Rekreasi dan Bangunan. Bogor (ID): Lembaga Pengabdian Kepada Masyarakat IPB Bekerjasama Dengan Badan Pertanahan Nasional.

Nurisjah S, Pramukanto Q. 2001. Perencanaan Kawasan untuk Pelestarian Lanskap dan Taman Sejarah. Departemen Arsitektur Lanskap Fakultas Pertanian Institut Pertanian Bogor. Bogor (ID).

Nurisjah S, Pramukanto Q. 2009. Penuntun Praktikum Perencanaan Lanskap. Departemen Arsitektur Lanskap Fakultas Pertanian Institut Pertanian Bogor. Bogor (ID). 